This is a provisional PDF only. Copyedited and fully formatted version will be made available soon.

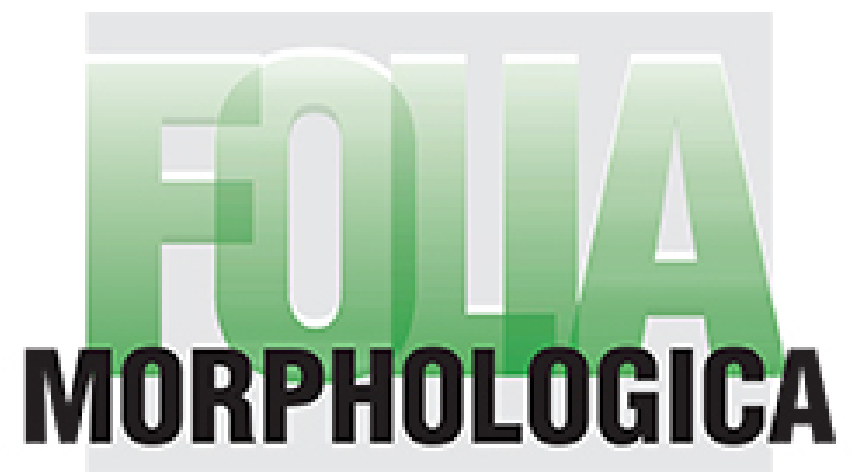

ISSN: 0015-5659

e-ISSN: $1644-3284$

\title{
The "sand watch" mandible
}

Authors: M. C. Rusu, M. D. Stoenescu, M. Butucescu, M. Săndulescu

DOI: $10.5603 /$ FM.a2022.0012

Article type: Case report

Submitted: $2021-10-26$

Accepted: $2022-01-25$

Published online: 2022-01-31

This article has been peer reviewed and published immediately upon acceptance.

It is an open access article, which means that it can be downloaded, printed, and distributed freely, provided the work is properly cited.

Articles in "Folia Morphologica" are listed in PubMed. 


\section{The "sand watch" mandible}

M.C. Rusu et al., The "sand watch” mandible

M.C. Rusu ${ }^{1}$, M.D. Stoenescu ${ }^{1,2}$, M. Butucescu ${ }^{3,4}$, M. Săndulescu ${ }^{5}$

${ }^{1}$ Division of Anatomy, Faculty of Dental Medicine, “Carol Davila” University of Medicine and Pharmacy, Bucharest, Romania

2“Carol Davila” Central Military Emergency University Hospital, Bucharest, Romania

${ }^{3}$ Division of Restorative Odontotherapy, Bucharest, Romania

${ }^{4}$ Faculty of Dental Medicine, “Carol Davila” University of Medicine and Pharmacy, Bucharest, Romania

${ }^{5}$ Division of Implant Prosthetic Therapy, Faculty of Dental Medicine, “Carol Davila” University of Medicine and Pharmacy, Bucharest, Romania

Address for correspondence: M.C. Rusu, MD, PhD (Med.), PhD (Biol.), Dr.Hab., Prof., “Carol Davila” University of Medicine and Pharmacy, 8 Eroilor Sanitari Blvd., RO-76241, Bucharest, Romania, tel: +40722363705, e-mail: mugurel.rusu@umfcd.ro; anatomon@gmail.com

\section{Abstract}

The lingual surface of the mandible's body is commonly indicated as presenting the submandibular and sublingual fossae, which are separated by the mylohyoid line. The mylohyoid line attaches to the mylohyoid muscle (MM). Less attention has been paid to the 'mylohyoid boutonnières', which allow the 'sublingual buttons' to pass through the MM in the submandibular space. The cone beam computed tomography (CBCT) files of patients 
were routinely examined for anatomical studies. Two cases were found with unexpected morphologies of the mandible's body - the mylohyoid lines were incomplete anteriorly, and herniated sublingual tissue determined an additional fossa inferior to that line in the premolar region. That fossa was termed the 'accessory submandibular fossa'. It determined on coronal slices a 'sand watch' contour of the mandible’s body. With such a peculiar morphology, the mandible is more prone to fracture. Moreover, when inserting endosseous implants, the procedure should be carefully personalised in such rare cases.

\section{Key words: mandible, CBCT, mental foramen, premolar teeth, sublingual fossa, endosseous implants}

\section{INTRODUCTION}

On the internal surface of the mandible's body is the mylohyoid line, which separates the submandibular and sublingual fossae and normally courses toward the digastric fossa (Figure 1). The lingual tuberosity (LT) appears as a bony shelf located lingual to the mandibular molars in some individuals, at the posterior extremity of the mylohyoid line [8]. Greatly enlarged LTs prevent the proper denture base extension [8]. Commonly, the LT does not extend on the lingual side of the mandibular premolars. The two fossae are occupied, respectively, by the submandibular (SMG) and sublingual glands (SLG). The mylohyoid line is the origin of the mylohyoid muscle (MM), which is an anterior suprahyoid muscle separating the submandibular and sublingual spaces [14]. A deficiency or hiatus on the part of the MM could lead to the penetration of the SLG [10]. This was found in up to $42 \%$ of 150 cadavers $[10,13]$.

We hereby report an unexpected morphology for the mandible's body in which the mylohyoid line was incomplete anteriorly and the herniated sublingual tissue determined an additional fossa inferior to that line, in the premolar region.

\section{MATERIALS AND METHOD}

The archived cone-beam computed tomography (CBCT) files of two patients, a 56 years-old male and a 61 years-old female were documented for a peculiar morphology of the mandible. The subjects were routinely scanned, according to the manufacturer instructions 
using an iCat CBCT machine (Imaging Sciences International [Hatfield, PA, USA]) with the settings: resolution 0.250, FOV 130, and image matrix size 640x640. The CBCT files were exported as single uncompressed DICOM files, which were analysed with the Planmeca Romexis Viewer 3.5.0.R software, as in other previous studies [17-19]. There were evaluated the two-dimensional planar cuts as well as three-dimensional volume renderings. Relevant results were exported as image files (*.tif). The patients have given written informed consents for use of medical data if anonymized. The responsible authorities ( $2^{\text {nd }}$ affiliation of the $2^{\text {nd }}$ author) approved the study (approval no.372/18.03.2020).

\section{RESULTS}

In the first case, the male (Figure 2), the mandible was completely dentate. On the inner aspect of each hemimandible, left and right, LTs were found at the level of all molars. The posterior segments of the mylohyoid lines were applied on the LTs. At the level of the molars, the submandibular fossae were identified. However, on each side, the mylohyoid line continued toward the mental spine, not descending toward the digastric fossa. Beneath that line and anterior to the submandibular fossa accessory submandibular fossae, left and right, were identified in the premolar regions. Both mylohyoid lines were indented correspondingly. On each side, the mental foramen was located at the level of the second mandibular premolar. On coronal cuts through the mental foramina, on each side, a "sand watch" contour of the mandible was identified due to the lingual cortical plate of the accessory submandibular fossa, which reached extremely close to the respective mental foramen.

In the second case, the female (Figure 3), the mandible was partly edentulous. On the right side, the $1^{\text {st }}$ mandibular premolar and all the molars were missing. On the left side, the $2^{\text {nd }}$ premolar and the $3^{\text {rd }}$ molar were missing. The inner side of each hemimandible had an evident mylohyoid line just in the posterior regions, at the level of the molars. At the level of the premolars, on each side, accessory submandibular fossae were found. As in the other case, the coronal cuts revealed a "sand watch" aspect of the mandible's body. In this case, as in the previous one, the coronal cuts revealed incomplete mandibular attachments of the MMs, allowing protrusions of the sublingual tissues (sublingual buttons) to descend and occupy the accessory submandibular fossae.

\section{DISCUSSION}


Gaughran (1963) observed, in dissections of the submandibular space, a 'mass of tissue lying between the mandible laterally and the MM medially', which was seen 'to continue through the MM, passing into the paralingual compartment' [6]. He documented the standard gross anatomy textbooks at that time and observed that this anatomical condition was described by Henle (1871), Poirier (1900), Eisler (1912), Quain (1923), Morris (1942), Testut and Latarjet (1948), Pernkopf (1952), Lanz and Wachsmuth (1955), and Meyer (1958) (all quoted in [6]). Gaughran also studied previous reports and found that the first hint regarding a hiatus on the part of the MM belongs to Forget (1870) (quoted in [6]). The following observation on the part of Gaughran, in 1963, is still valid: 'Looking at the clinical literature concerned with anatomical studies of the submandibular and paralingual regions one obtains the overwhelming impression of a complete mylohyoid barrier between the two compartments.' When Gaughran studied 162 cadavers (324 half-heads), he found, in 36.1\%, 'distinct masses of tissue resting on the inferior surface of the mylohyoid muscle', which he termed sublingual buttons located either in the anterior half or in the anterior two thirds of the MM, in the cleft between that muscle and mandible's body [6]. Therefore, such sublingual buttons can bona fide determine the bone accessory submandibular fossae, such as those reported here. Most of these buttons were processes of the sublingual gland, which penetrated the MM through a "mylohyoid boutonnière" and occurred bilaterally in just $19 \%$ of cases [6]. Through that boutonnière were also found, exclusively, fat herniations [6]. Branches of the submental vessels were also found within the boutonnière [6,13,22]. In just $0.9 \%$ of cases, neither glandular tissue nor fat was found within the boutonnière of the MM [6]. Double sublingual buttons were found, with one being fatty and the other being glandular [5].

The prevalence of the mylohyoid boutonnière was reviewed by Ahmed et al. (2009) and ranged from 30\% to 80\% [1]. However, Windisch et al. (2004) found herniations and deficiencies of the MM in just 12.2\% of 205 cadavers [21]. To our knowledge, sublingual buttons were not previously observed to determine accessory submandibular fossae on the body of the mandible $[13,20,21]$.

The accessory submandibular fossae we found occurred bilaterally. This could be suggestive of developmental symmetry on the part of the mylohyoid boutonnières. Such unexpected fossae of the inner cortical plate of the body of mandible, if unidentified, increase the risks of iatrogenic events during the placement of endosseous implants in the mandible; therefore, the pronounced lingual concavity of the bony plate should be taken into account and correlated with the length and inclination of an implant inserted in the premolar region of the mandible. 
The region of the sublingual fossa is highly vulnerable to perforation during implant placement procedures [11]. While perforating the lingual plate of the mandible in the molar region may damage the salivary gland, a perforation in the premolar area carries a much higher risk because the osteotomy drill may damage the arterial plexus formed by the sublingual and submental arteries. There are several cases reported in the literature with a potentially serious risk for the patient $[4,7,12,15]$, and this concavity of the mandible in the premolar area may predispose patients to this kind of accident [3].

Moreover, it is well-known that a severe complication related to endosteal implants is the fracture of the edentulous, resorbed mandible $[2,16]$. The fragility of the mandible may increase not only in edentulous mandibles but also in "sand watch" mandibles, such as those reported herein. Overloading such a "sand watch" mandible could also lead to an unexpected fracture during mastication or during a traumatic event, such as violence or an accident. Such mandibular fractures more commonly occur in the weaker areas of the mandible [9].

Clinicians, as well as students and teachers, should pay attention to individual anatomical characteristics [23]. Such "sand watch" mandibles can be identified in CBCT, and the treatment plan for such should be personalised.

\section{REFERENCES}

1. Ahmed M, Strauss M, Kassaie A, Shotelersuk V, DeGuzman R (2009) Bilateral submandibular gland aplasia with clinico-radiological mass due to prolapsing sublingual salivary tissue through mylohyoid boutonniere: A case report and review. Dentomaxillofac Radiol, 38:121-124. doi:10.1259/dmfr/63254814, https://www.ncbi.nlm.nih.gov/pubmed/19176656

2. Chrcanovic BR, Custodio AL (2009) Mandibular fractures associated with endosteal implants. Oral Maxillofac Surg, 13:231-238. doi:10.1007/s10006-009-0171-7, https://www.ncbi.nlm.nih.gov/pubmed/19789898

3. Citir M, Gunduz K, Kasap P (2020) Investigation the anterior mandibular lingual concavity by using cone-beam computed tomography. Folia Morphol (Warsz), doi:10.5603/FM.a2020.0128, https://www.ncbi.nlm.nih.gov/pubmed/33084005; https://journals.viamedica.pl/folia morphologica/article/download/FM.a2020.0128/52241

4. Dubois L, de Lange J, Baas E, Van Ingen J (2010) Excessive bleeding in the floor of the mouth after endosseus implant placement: A report of two cases. Int J Oral Maxillofac Surg, 39:412-415. doi:10.1016/j.ijom.2009.07.062, https://www.ncbi.nlm.nih.gov/pubmed/20079609

5. Engel JD, Harn SD, Cohen DM (1987) Mylohyoid herniation: Gross and histologic evaluation with clinical correlation. Oral Surg Oral Med Oral Pathol, 63:55-59. doi:10.1016/0030-

4220(87)90340-9, https://www.ncbi.nlm.nih.gov/pubmed/3468466

6. Gaughran GR (1963) Mylohyoid boutonni'ere and sublingual bouton. J Anat, 97:565-568. https://www.ncbi.nlm.nih.gov/pubmed/14064098 
7. Kalpidis CD, Konstantinidis AB (2005) Critical hemorrhage in the floor of the mouth during implant placement in the first mandibular premolar position: A case report. Implant Dent, 14:117-124. http://www.ncbi.nlm.nih.gov/pubmed/15968182

8. Kelly EK (1966) The prosthodontist, the oral surgeon, and the denture-supporting tissues. J Prosthet Dent, 16:464-478. doi:10.1016/0022-3913(66)90051-5,

https://www.ncbi.nlm.nih.gov/pubmed/5218889

9. Khan AA, Banerjee A, Mbamalu D (2009) Mandibular fracture caused by mastication. Emerg Med J, 26:153. doi:10.1136/emj.2008.062299, https://www.ncbi.nlm.nih.gov/pubmed/19164647

10. Kiesler K, Gugatschka M, Friedrich G (2007) Incidence and clinical relevance of herniation of the mylohyoid muscle with penetration of the sublingual gland. Eur Arch Otorhinolaryngol, 264:10711074. doi:10.1007/s00405-007-0321-1, https://www.ncbi.nlm.nih.gov/pubmed/17479273

11. Kusum CK, Mody PV, Indrajeet, Nooji D, Rao SK, Wankhade BG (2015) Interforaminal hemorrhage during anterior mandibular implant placement: An overview. Dent Res J (Isfahan), 12:291-300. doi:10.4103/1735-3327.161422, https://www.ncbi.nlm.nih.gov/pubmed/26288617

12. Mordenfeld A, Andersson L, Bergstrom B (1997) Hemorrhage in the floor of the mouth during implant placement in the edentulous mandible: A case report. Int J Oral Maxillofac Implants, 12:558561. https://www.ncbi.nlm.nih.gov/pubmed/9274086

13. Nathan H, Luchansky E (1985) Sublingual gland herniation through the mylohyoid muscle. Oral Surg Oral Med Oral Pathol, 59:21-23. doi:10.1016/0030-4220(85)90109-4, https://www.ncbi.nlm.nih.gov/pubmed/3856203

14. Otonari-Yamamoto M, Nakajima K, Tsuji Y, Curtin HD, Hanyuda H, Okano T, Sano TJOR (2011) Mylohyoid muscle defects: Comparison of ct findings and dissected specimens. Oral Radiol, 27:50-56. doi:10.1007/s11282-011-0066-9,

15. Pigadas N, Simoes P, Tuffin JR (2009) Massive sublingual haematoma following osseointegrated implant placement in the anterior mandible. Br Dent J, 206:67-68. doi:10.1038/sj.bdj.2009.2, https://www.ncbi.nlm.nih.gov/pubmed/19165260

16. Raghoebar GM, Stellingsma K, Batenburg RH, Vissink A (2000) Etiology and management of mandibular fractures associated with endosteal implants in the atrophic mandible. Oral Surg Oral Med Oral Pathol Oral Radiol Endod, 89:553-559. doi:10.1067/moe.2000.105237, https://www.ncbi.nlm.nih.gov/pubmed/10807710

17. Rusu MC, Sandulescu M, Sava CJ, Dinca D (2018) Bifid and secondary superior nasal turbinates. Folia Morphol (Warsz), doi:10.5603/FM.a2018.0047, http://www.ncbi.nlm.nih.gov/pubmed/29802719

18. Rusu MC, Sava CJ, Ilie AC, Sandulescu M, Dinca D (2019) Agger nasi cells versus lacrimal cells and uncinate bullae in cone-beam computed tomography. Ear Nose Throat J, 98:334-339. doi:https://doi.org/10.1177/0145561319840836, http://www.ncbi.nlm.nih.gov/pubmed/31012345 19. Sava CJ, Rusu MC, Sandulescu M, Dinca D (2018) Vertical and sagittal combinations of concha bullosa media and paradoxical middle turbinate. Surg Radiol Anat, 40:847-853.

doi:10.1007/s00276-018-1998-0, http://www.ncbi.nlm.nih.gov/pubmed/29502247

20. White DK, Davidson HC, Harnsberger HR, Haller J, Kamya A (2001) Accessory salivary tissue in the mylohyoid boutonniere: A clinical and radiologic pseudolesion of the oral cavity. AJNR Am J Neuroradiol, 22:406-412. https://www.ncbi.nlm.nih.gov/pubmed/11156791

21. Windisch G, Weiglein AH, Kiesler K (2004) Herniation of the mylohyoid muscle. J Craniofac Surg, 15:566-569. doi:10.1097/00001665-200407000-00007, https://www.ncbi.nlm.nih.gov/pubmed/15213531

22. Zdilla MJ, Bender-Heine AN, Lambert HW, Hunter DD (2021) Clinical implications of the submental and sublingual arteries in relation to the mylohyoid boutonniere. Otolaryngol Head Neck 
Surg, 164:322-327. doi:10.1177/0194599820939852,

https://www.ncbi.nlm.nih.gov/pubmed/32689891

23. Żytkowski A, Tubbs RS, Iwanaga J, Clarke E, Polguj M, Wysiadecki GJTRiA (2021)

Anatomical normality and variability: Historical perspective and methodological considerations.

Transl Res Anat, 23:1-10.

Figure 1. Internal view of a normal right hemimandible. Three-dimensional CT volume rendering; 1 - mylohyoid line; 2 — sublingual fossa; 3 — submandibular fossa; 4 digastric fossa; 5 - mental spine.

Figure 2. Case \#1. The bilateral anomalous morphology of the „sand watch” mandible is documented on digital orthopantomogram (A), coronal cuts, three-dimensional rendering (B, posterior view) and orthogonal (C, left side; D, right side), and complete three-dimensional rendering (E, posterior view). The arrowheads indicate the mental foramen, the arrows indicate the deep accessory submandibular fossae beneath the premolar alveoli. The 2nd mandibular premolar is indicated $(*)$.

Figure 3. Case \#2. Three-dimensional renderings of the right (A) and left (B) hemimandible. Coronal cut through the accessory submandibular fossa (C). Coronal cut at the level of the mental foramina — the „sand watch” aspect of the mandible; 1 - mylohyoid line; 2 submandibular fossa; 3 - accessory submandibular fossa; 4 - bilateral sublingual buttons; 5 — mental foramina. 


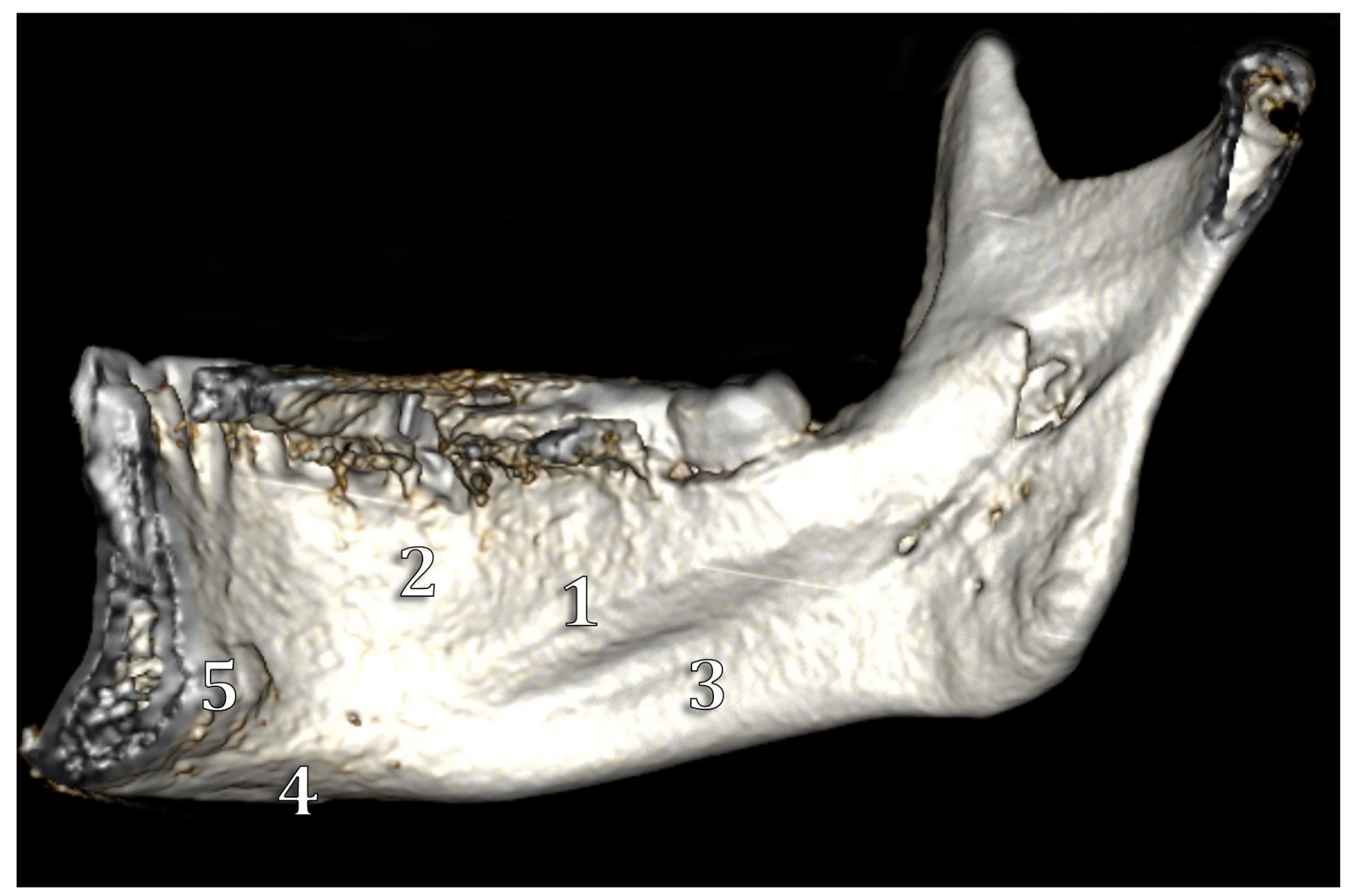




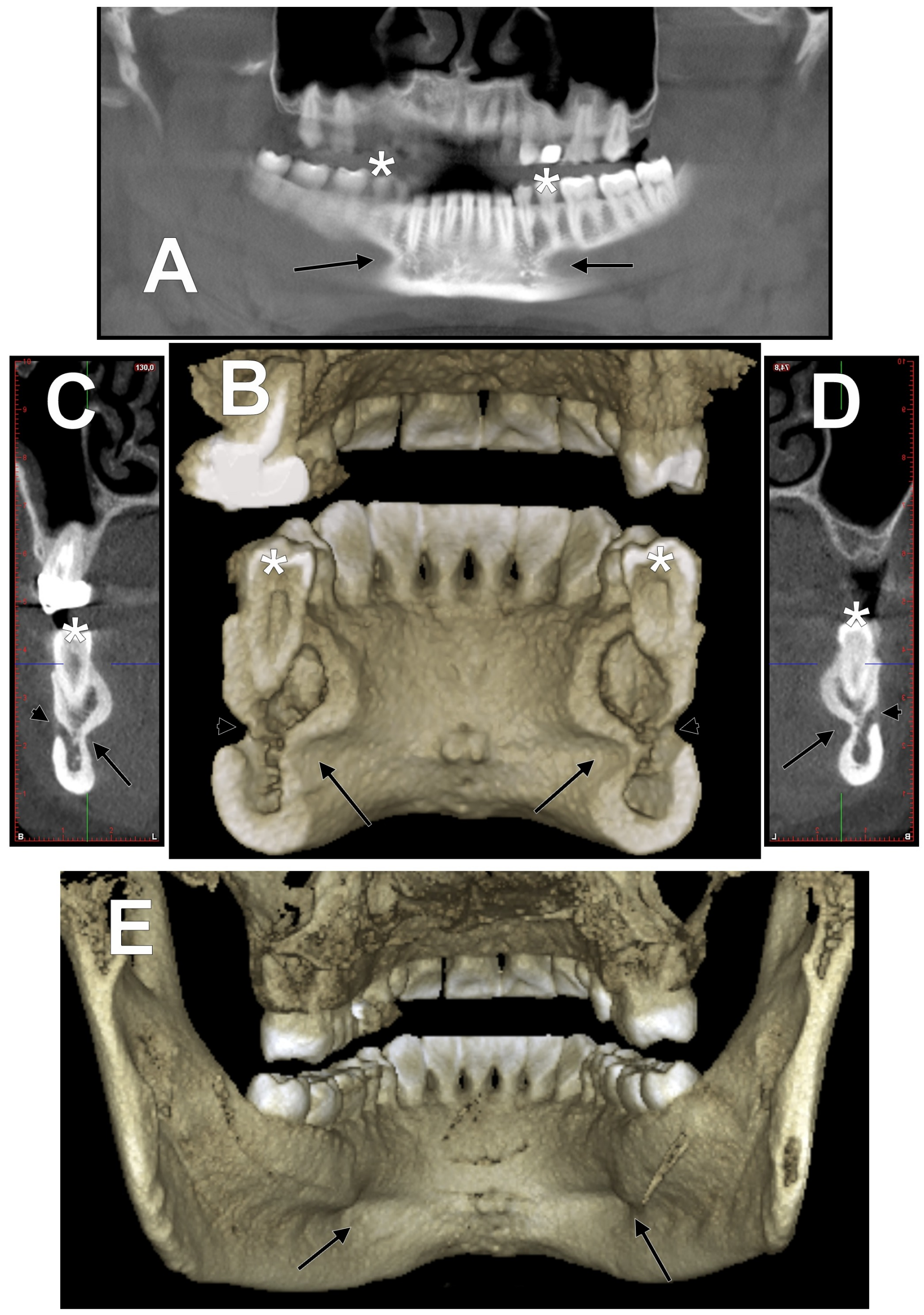



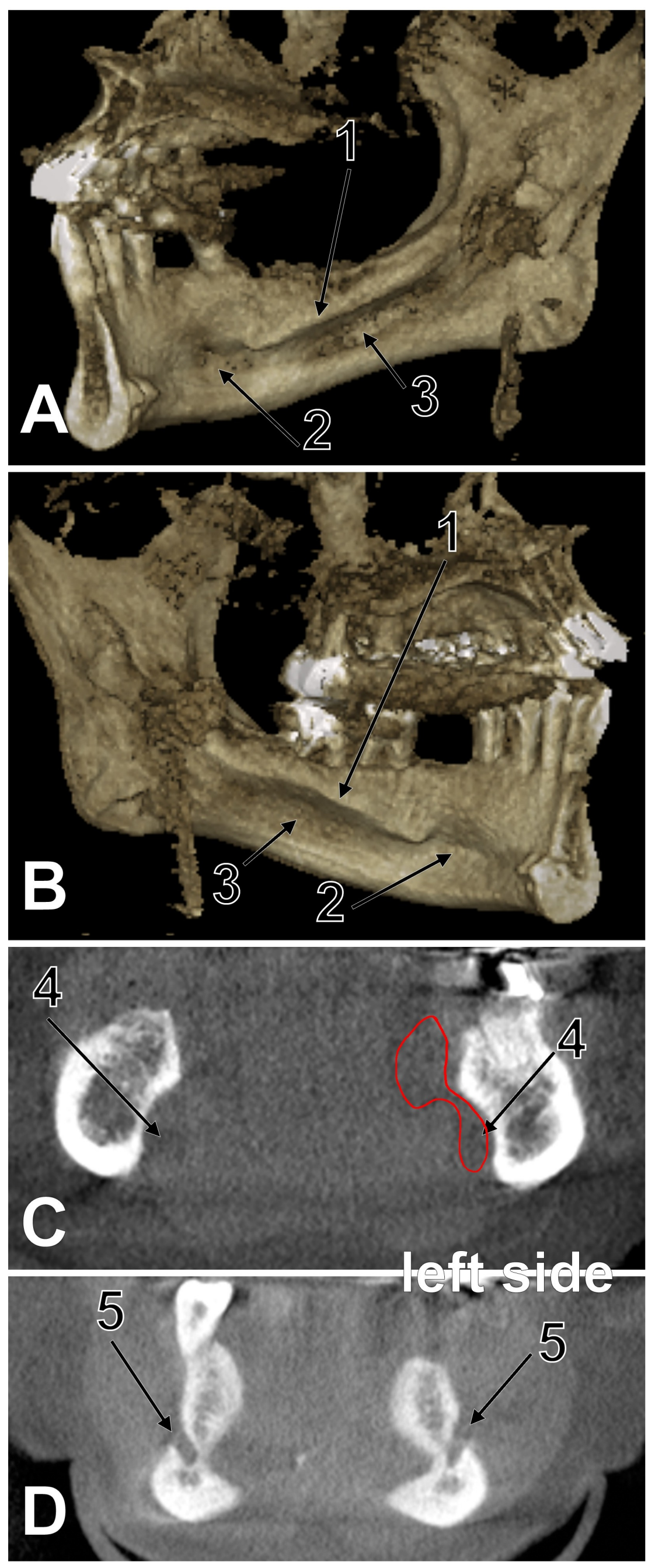